\title{
Distributed Energetic Resources: Trend, Control and Operation
}

\author{
Cesar Hernandez ${ }^{\# 1}$, Víctor Gómez ${ }^{* 2}$, Edwin Rivas ${ }^{\# 3}$ \\ \#Universidad Distrital Francisco José de Caldas, Bogotá-Colombia. \\ 1cahernandezs@udistrital.edu.co; \\ 33rivas@udistrital.edu.co \\ *Schneider Electric, Bogotá-Colombia. \\ 22victor.gomez@schneider-electric.com
}

\begin{abstract}
Humanity's growing energetic demand and the need for the electric fluid coming to not interconnected zones in the world has brought with it the deployment of a huge amount of researches related to the distributed generation, the distributed energetic resources, and the smart networks. Those have been approached as mechanisms for global growth and energetic supply. Thus, this article details the researches led by a significant number of experts who have definitely generated the fundamental pillars of evolution regarding network. Moreover, when it comes to its core, where the trend, the control and the operation of the new generation schemes, they provide the change from a traditional energetic system to a sustainable energetic system.
\end{abstract}

Keywords - Algorithms, renewable energy sources, distributed generation, artificial intelligence, microgrid.

\section{INTRODUCTION}

Nowadays, traditional energy systems face different types of issues such as the high amount of carbon dioxide (CO2), high generation costs, network tension variations, overloaded lines, dynamic stability issues, and service interruptions.[1],[2]. In order to face these issues, an innovative and very common approach is the generation of electric energy at a local level. This type of energy generation is called Distributed Energy (DG) and the resources that provide it are called Distributed Energetic Resources (DER)[3],[4]. In fact, due to the energy generation in proximity to the load centers, the distributed generation resources would solve the demand over the transmission networks. Today, different countries are trying to increase the penetration of distributed generation in their electronic networks. Each country attempts to use in the most appropriate way the distributed energetic resources based on its resources and conditions. Unfortunately, each DER type has its inconveniences. For example, a photovoltaic system cannot generate electricity for a continued $24 \mathrm{~h}$ period, because its energetic source is the sun, which does not provide radiation at all times. The same applies to wind power, because the wind currents are not constant, and therefore, the required speed is not fully available for the system's continued operation. Typically, intermittence is a disadvantage of the DG resources. That is why there's a need for integrating the DER which is crucial when providing high-quality electricity and satisfying the system's demand.[5],[6].

The DERs are classified into two categories: Dispatchable and not dispatchable. The first one is related to resources which output potency can be adjusted by the network operators. The second one indicates that the generated energy of the DERs cannot be adjusted by the network operators. For this last category, a particular example would the wind and solar generation units.

The Microgrids (MG) are an integrated way of DER, where the loads and storage units are installed for supplying energy to small communities such as universities, hospitals, schools, towns, paths, shopping malls, as well as industrial projects. Thus, it is possible to classify the generation-consumption relation. One of these classifications can be given by the type of resource used, which are mainly chosen in function of its availability in the installation place[7]. Also, they can be classified whether they have storage options or not. Typically, the MG has two types of functioning, manual or automatic in island mode[6],[8]. In a strict sense, on the island configuration, the MG is not connected to the electronic network; conversely, this one works independently. This MG type is quite useful for rural areas where electrification is complicated or not very profitable. On the other hand, the MG that works continually in the network allows having an aid or backup to other generation units in order to satisfy the network demand. Normally' the MG operation can be easily changed among these two modes. 


\section{Distributed ENERGETIC RESOURCES (DER)}

Currently, the DERs have a considerable attention due to the possibilities and versatility on their installation. Therefore, they have been highlighted for their adaptation capacity to the distribution system and also for its great capacity to reduce the carbon dioxide emissions, enhancing thus, the energy systems efficiency and reliability[9].

A definition that describes the DERs could be: small scale generation units, where it can be found photovoltaic solar systems, dump gasses, cogeneration, wind turbine and small-scale hydroelectric generation. Honestly, DERs have many advantages, but the intermittency of these resources is considered its main disadvantage. With this in mind, a need for developing great size storage systems is raised to be used to overcome those resources intermittency. At the same time, it incurs in a higher cost. As a consequence, the integration of the DERs is crucial for overcoming those inconveniences.

\section{A. Photovoltaic solar system}

Photovoltaic solar systems are a prominent renewable energy source. This is the second widest power supply, reason why by 2011, the global operative installed capacity of the photovoltaic solar energy reached 70GW[6]. This is ten times 2006's capacity with a 58\% annual growth average rate during that period. In consequence, by 2012, the operational global installed capacity reached $100 \mathrm{GW}$ [6]. Global annual photovoltaic production is considered one the common use renewable energy sources for MG systems[10].

\section{B. Wind power}

Nowadays, the use of wind power for generating energy is continually increasing. The implementation of wind turbines turns out to be one of the common use renewable energy sources for the MG systems. Its operating principle is based on the conversion of wind power from the wind current that flows through earth's surface in electric energy. Thus, depending on the control capacity, the wind turbine's operating systems are classified into variable speed wind turbines or constant speed wind turbines[11].

C. Fuel cells

Fuel cells convert chemical energy from a fuel directly into electric energy with high efficiency and lowtemperature results, producing low carbon emission[12]. In general, high efficiency depends on the type of system configuration. Its operating principle is similar to batteries. However, its main difference is based on the fact that the cells are designed being capable of supplying continually. This means it produces energy from an external fuel base which in the best scenario can be oxygen.

\section{Storage devices}

Energy storage devices, such as batteries, capacitors, and ultra-capacitors must be included in the operation of MGs, especially in island mode in order to lock the uninterrupted supply source during the disturbances and/or drastic load changes[13]. This is why these devices have a limited energy storage capacity due to their physical restrictions. The battery is a conventional storage technology, composed of one or more electrochemical cells, that turn chemical energy stored in an electrolyte into electric energy due to an oxidation-reduction electrochemical reaction[14]. The rechargeable battery is commonly used in the MG operation, but it requires an annual maintenance and has a higher environmental impact, as well as a lower lifetime compared to technologies of devices storage such as the super-capacitors.

\section{III.DER'S TREND}

The use of DERs on electric energy systems is continually increasing. This is why it is imperative that research programs aim to align the sector needs among the goodness of implementing this type of low contamination technologies and thus, a low environmental impact[15]. Once a coherent articulation among the agents that interact around the energetic consumption value chain is made, it will be easier to integrate the high scale DERs.

On the other hand, the need for guaranteeing a service that is governed by quality, efficiency and continuity principles opens the gap for seeing the development scenarios of the market for DER and thus, visualize the potential clients and the main needs of the operators and marketers of electric energy.

\section{A. Study cases}

In [16]presents an MG in transitory state and permanent regimen, used for supplying electric energy to an industrial complex. In the stationary state, the system tensions and load flow are determined in different conditions such as:

- with and without DER

- with changes in the load levels

- with losses in the generation systems based on micro turbines 
The results from the analysis in stationary state demonstrated for all scenarios, the insertion of nonconventional energy sources significantly enhances the system's tension profiles. Likewise, it reduces the reactive power flow and the losses caused by that one. This is why researches on [16] developed the analysis in the EMTP computational tool, especiallyidealized for the study of a system in transitory state. The dynamic analysis results evidenced the efficiency of the local tension regulator during the load changes and distribution.

In [17] analyzes diverse items related to the simulation and design of the MGs, concluding there are new methods and software required for overcoming the challenges of this technology types, because the existing energy system analysis methods cannot provide the necessary tools in order to gather objective conclusions. As a consequence, such research shares a comparison in regards to a gas turbine generator system developed on [18]. As a result, the use of gas turbine generators lower than $100 \mathrm{~kW}$, turns out to be expensive when it comes to the interconnection and especially in the equipment in charge of the system's supervision and protection. Despite its high investment cost, its efficiency is low. While using the $250-500 \mathrm{~kW}$ gas turbine with high speed axial flow generators is considered an excellent option in order to satisfy the electricity, heating, refrigeration needs for industrial clients and light marketers.

In [19]defines the MG as an aggregation of electric loads and non-conventional generators (renewable energy)[6], consequently some of them generate excessive heat that can be used for domestic and industrial heating purposes which it turns into the enhancement of the MG system's general efficiency. This research also details the Energy Management System function (EMS) as a decision-making tool, used for determining the optimum functioning of the generators for producing electricity and heat.[6]. On the other hand[20], implemented a tool for distributing the energy resources adopting the client's model and which name was assigned as (DER-CAM) model in order to study the economy and small scale operation (less than $500 \mathrm{~kW}$ ). Also[21], implements the DER-CAM model, and discusses the electricity issue as a learned lesson or reasoning based on cases from the lived experience of 2003's summer in North America, which made notorious the incapacity of the existing electronic networks for answering to the continuous growth of energetic demand.

Researches developed on [22] and [23] show that the research in different DERs can solve the problem related to the individual DERs operation, because these interconnect to each other with the load through power electronic converters and they are controlled by using microprocessors or reconfigurable architectures. As a consequence, these two researches provided a vision of the environmental benefits of using MG. In [22] presents the results from an experiment in laboratory scale, making an MG in the University of WisconsinMadison, while on [23] DER-CAM models were applied to users in order to check the MG concept.

In [24] describes the main characteristics of the technologies so that later on a control framework is proposed based on agents for DER and MG. Later, there is an assessment of the system and the proposed method through an integrated DER simulation, which can be used in a single MG as a modular power of the generation units. Simulation results showed the proposed method is effective for coordinating the different DERs, because it allows managing the load profile and the system's tension variations. In [25]proposes to refer a strategy for assigning the DERs on MG. In such, the problem is raised as a non-linearprogramming and then it is resolved by an artificial intelligence algorithm. On the other hand, the post [26], highly valued for its great effort onto developing researches aiming to integrate in a high scale the DERs in the low tension networks, allowing through this research knowing the selection of results that include development and enhancement to the operation and the generation's strategy control as well as the analysis of communication requirements, the development of continuous enhancement methods for reliability measurements, and last but not least, a sample of the first actual low tension installation integrating DER.

In [27] shows the highlighted technical challenges which are derived from the expansion of DERs in Europe, more specifically in France, considering the regulatory and technical environment. In [28] examines the research activities about the DERs integration in electronic networks of the future in Europe. In [29] presents some reference items and network resources for the distributed modeling among integration issues with energetic resources. In [25] and [30] proposed a new method for hierarchically integrating a heterogeneous small size DER set in the existing electric energy distribution system. The proposed method uses two links, one of them based on direct current (CD) and the second one based on alternate current (CA) with the purpose of adding a three hierarchy level energetic articulation to the DERs through advanced devices consisting of power a proper control strategies, this is why the main need for the first DERs is to integrate the systems through CA-CD or CD-CD converters.

In [31]detailed the research work and studies about the MG technology in order to gather a description of the main configurations functioning for this type of technologies, such as the MG situation in the market environment. In [32] Proposes a new approach for the modeling of a Smart and auto-configurable system through the automatic management of demand. The proposed system uses the MG's central controller for managing the smart loads with the purpose of decreasing the system's global demand, particularly during high load peak periods. Results showed this conducts to increasing the system's reliability and lowering costs. 
In [33]informs that the progress upon Information and Communication Technologies (ITC) provides help in terms of looking for viable and profitable solutions for some functioning issues, surveillance, control and protection of the MG systems. In [34]uses a linear programming approach for modeling an MG consisting of a DER mixture, as well as response systems to energy storage demand and the utilization of actual residential energy consumption data.

Simulation results detail the effectiveness of integrating diverse DERs on reducing demand fluctuations and evidencing the great capacity to reinforce the energetic balance. Thus, such research about the base of the MG system simulation results, led to conclude it is possible to contribute to lowering $\mathrm{CO} 2$ emissions significantly.

In [35] explains the importance of integrating the fluctuant energy from non-conventional supply sources with the electronic network, through smart networks, as long as this type of solution is adapted as a sustainable means to the population's energetic demand. As a consequence [36] and [37] discuss the main current challenges and the possible solutions for the ongoing issues in terms of developing the smart energy distribution networks. Therefore, researches made upon a scientific scope have detailed a constant review of the main needs for guaranteeing sophisticated communication systems, evidencing the main relevant aspect for interconnecting the information with great power system infrastructures. With this in mind, not only the power systems articulation with the communications would be guaranteed, but also, a high importance would be given to the Energetic Management Systems on coordinating and optimizing the DERs.

In [38]presents a comparison of the low tension systems which feeding signals can be alternate and/or continuous, in function of MG operation characteristics, which includes the renewable energy sources and the energy storage systems. However, it also describes the study of system load based on the economical, technical and environmental aspects, identifying the main benefits of integrating all actors from the energetic value chain. Likewise, as a result from the research, it was detected that the low tension systems for a CA and CD MG, among the conversion devices, can reach a high reliability and efficiency, guaranteeing the operation variables from the feeding source to be governed by the principles of quality for the future's energy systems. Thus, researchers on [39] have proposed a simulation based on the optimization for determining the allocation and capacity of the DERs in an energy distribution network with an imperfect network connection. This way, the researchers used the Dynamic Optimus Power Flow (DOPF) where the first one aims to calculate the cost and reliability level from the system during one year, and then the second one is destined for reducing the costs to the minimum. To satisfy the reliability requirements, they used the Particles Swarm Optimization (PSO) which uses as an output the first layer in order to find the optimum location and the wind turbines capacity, photovoltaic panels and network scale batteries[6],[40],[41].

In [42]proposes a Mixed Integer Linear Programming model for designing a DER system that satisfies the electricity and heating needs from a group of commercial and residential buildings, reducing the annual investment and operational cost to the minimum. Likewise, researchers on [43] have proposed a new method in order to determine the optimum size of the energy storage system, by using short-term overloaded batteries. The results from the application of the new approach showed there is an opportunity for quick injection or abortion power that supports the MG to restore the generation load balance. Likewise, [44] supports the previous idea through the modeling, planning and energy management of the MGs, where it includes the renewable energy in order to satisfy the refrigeration, heating and electric load needs. According to the authors, this type of MG can resolve some problems related to the catering in non-interconnected areas.

\section{IV.MG OPERATION}

Recent results highlight the MG, which is technically defined as an energy distribution network that comprehends multiple electric and DER loads, which can work independently or jointly with the main network, through one or more common coupling spots. That is how the MGs can operate all DERs, including the energy storage and load components in a controlled way and coordinate the optimization, system performance and operating savings by interacting with the main network in real time [45]. This allows visualizing the enormous challenges in terms of technological and scientific infrastructure demanded by the implementation of the traditional electric schemes. Thus, the main researches upon MG control, operation and supervision technologies are presented as follows.

Micro-sources (MS) and renewable energies refer to the integration of DER to MG where the electric energy distribution network must respond to dynamic changes from the generation, transmission, distribution and storage of energy. However, a disadvantage of MSs is that they are not suitable for electronic networks direct connection. Therefore, this type of technologies must work among (DC/AC or AC/DC/AC) power electronic converters. In general, in MG's operation, setting the inverter's control is the most important task [46]. The MG operating connected to the network, where the distributed energy sources are operated in parallel to the main network. Therefore, the MG extracts or supplies energy from or to the main network, in function of the energetic offer and demand. In this type of functioning, the voltage and frequency are determined by the main network. Thus, the central controller automatically configures the MG system, so it is independently connected to the 
network. At this point, the tension and frequency variation turn out to be more prominent; therefore, the MS controller for each DER must control its tension and frequency to maintain the MG's stability [47].

Central Controllers (CC) for MG's implement control strategies based on: optimization algorithms control expert systems, decentralized and hierarchic control. These are considered appropriate strategies which are aligned to the system's optimization through a Linear Programming (LP) or Non-linear Programming (NLP). On LP algorithms, the objective function and restrictions are the two lineal equations, while on the PNL, the objective functions are non-linear equations and the limitations are lineal equations[48],[49]. However, the expert system control is used for mitigating the optimization control disadvantage in real time, because the last one turns into an excessive computational load when processing data. This leads to a time increase for reaching a solution depending on the complexity and the system's nonlinearity. In this control method, the artificial intelligence (for example, diffuse logic), which resembles human reasoning, can be used for the design of $\mathrm{CC}[32],[47]$.

Reseraches on [50] analyzed the performance in transitory and stable state for an MG composed by photovoltaic solar panels, with a Maximum Power Point (MPP) and a wind turbine. As a consequence, the research had as an objective adopting a strategy for controlling tension and frequency magnitudes from the two selected renewable energy sources[6]. Concluding that in the network connection mode and the proposed control method they maintain stability during the network connection and disconnection, and in island mode under different loads and weather conditions, frequency and tension are preserved close to their nominal values. Likewise, [51] proposed a new quality compensator of electric power with interface for its use with MG applications on three-phase systems, using a wand with two inverters optimally controlled.

In [52] developed a computational tool for designing the DER's sizes in an MG, from the autonomous mode functioning or distribution network island with radial topology. This strategy was approached by using a genetic algorithm helped by the computational tool MATLAB. Its proposed methodology design determines the sizing of the DERs under three limitations, which are: isolated operation mode, variation of generation and demand during summer and winter[6]. Likewise, [53] proposes a control approach for induction generators doubly fed, aiming to enhance the voltage and primary frequency controls, under the island mode operation configuration.

In [54] They propose a control strategy for easing the active and reactive power interchange within the MG using back-to-back converters. Their proposed methodology controls MG's functioning in two different modes, which are determined according to the amount of required energy in the system. In the first mode, a set of backto-back converters are used to enable specific quantities flows of energy demanded by the MG. Thus, energy excess is supplied to the network so they can later be regulated by the distributed generators. On the other hand, the second option is the potency's high demand in the MG, where energy generation by DG reaches its maximum limit and the rest of the energy demand is supplied by utility.

On [55] they describe the dynamic, implementation and operation of the inverters that simulate the synchronverters, usually used for auxiliary services, because they can easily operate in the two functioning modes of the MG, and therefore, they provide an optimum solution for controlling smart networks (SG). This is how [56] proposed a multi-agent system for managing DER's energy from an MG system in island mode. The proposed algorithm makes a resources planning and the integrated energetic management for the MG through three steps:

$\checkmark$ The first step is to program each MG separately in order to satisfy its load demand

$\checkmark$ The second step is to determine the best possible offers for exporting energy to the distribution system and competing in an energy sale market

$\checkmark$ The third step is to program once again each MG individually to satisfy the total load demand.

The authors on [57] propose a hybrid control strategy consisting of both states, continuous and discreet, valued by the fact that both of them affect the dynamic behavior of the control system for the functioning or operability of the MG. Likewise, the post [58] proposes an expert controller for planning an energy storage system in a hybrid wind-diesel system where the electric loads disconnection can be reduced to its minimum since they can cause over tensions or issues to the system's balance. However, the research found out that using the storage system and the proposed controller minimizes the wasted energy through the load, and therefore, it minimizes: the required diesel demand, the operating costs and the $\mathrm{CO} 2$ emissions.

On [59] they propose a general approach regarding normalization. Starting with the three research pillars, where the hierarchic operation consists of three control levels:

$\checkmark$ The first control level is based on the droop method.

$\checkmark$ The second control level allows the restoration of deviations caused by the first control level

$\checkmark$ The third control level manages the energy flow among the MG and the external electric distribution system. 
On [60] authors developed a new energy management method for the active power transferring in network connected mode, with two functions: the first one, where the MG is able to adjust the disposed electric generation line for the loads, which reduces the fuel consumption and therefore, the $\mathrm{CO} 2$ emissions costs. The second one, implements a low cost or MS controller.

In [61]proposed a control strategy for an MG that includes the renewable energy generation and the implementation of electric vehicles in both functioning modes. The proposed control method uses a singlemaster operations control strategy, in isolated mode and a current control strategy in connected to network mode. This allows the DERs to work in parallel with the main network. In [62]proposes a cooperation frequency control approach which includes a central MG controller and the MS controller. As a consequence, there is a transition without any issues from its connection to the network for the independent mode, and therefore, it enhances the stability as well as the primary and secondary frequency control.

In [63] shows the decentralized and hierarchic control techniques for MG that is currently being implemented. Nevertheless, there are numerous researches where the main problems and solutions about MG energy quality are summarized, as well as researches regarding the distributed energy storage and the interaction of CA and CD converters in the centralized or distributed electronic networks.

In [64] Presents an energy management local strategy with a proposed model for photovoltaic units and MG storage units. This strategy determines the reference value of the demanded power and the functioning of each generation source from the electric system. The results have shown that the proposed strategy offers a soft or weak output power against the continuous changes demanded by the load. On [65] greenhouse effect gasses emissions by non-conventional technologies have been reduced to the minimum by using the distributed energetic resources. However, no studies have been made yet upon the quantitative and exact way, on which are the environmental issues and its repercussion to all energetic chain pillars. For now, results confirm that distributed renewable energy will be the way out for the lethargic dependence being offered by the fossil fuels in industrialization's accelerated chain.

In [66]presents a new control strategy for enhancing the stability of DG's integrated systems. This strategy considers the compensation of instant variables in the reference current from the generation units. The proposed control strategy offers a fast dynamic response. In [67] proposes a detection strategy on remote island configuration mode, resulting in efficiency and quickness in terms of a reply for for DG units based on photovoltaic systems. Obtained results show that the proposed control strategy works according to the frame time required by the users' load profiles. On [68] authors propose the use of two programs for responding to fuel change demand in plug-in hybrid vehicles with the purpose of increasing energy's management flexibility. On [69] the effects of the thermal restrictions in the planning of distributed energy units have been investigated, in order to elaborate on the planning of DER units. On [70] sustainable energy strategies have been applied to small MG's, while there's a high penetration of distributed generation resources based on renewable energy. Thus, the authors suggest the energetic policy pays more attention to small scale networks to mitigate global warming and the effects of climate change.

\section{CONCLUSIONS}

As time passes, microgrids are being more adopted as a modernization and/or evolution of conventional electronic networks, despite the world's energetic needs and considering the significant amount of populations that do not have access to this basic service yet. This service turns out to be very necessary for connecting people around the globe, where the knowledge and learning are more than attached to energetic dependence. Because of that, numerous researches explain the microgrids are a viable method for integrating the different distributed energetic resources to the low tension networks. This way, local demand of populations is satisfied and likewise, carbon emissions are lowered.

The implementation of different distributed energy resources and different energy storage technologies has its operation and control method for producing a reliable and steady output. In other words, they will be attached to diverse technical problems on its functioning and monitoring. These problems are considered to be challenges from the reliable a desirable operation of microgrids. As a consequence, these challenges motivated the authors to review previous work made by researchers on this matter, either on distributed energy resources in microgrid systems or operation and control strategies.

On the other hand, from the economic perspective, the total cost of distributed energy resources is still high, which turns out to be an implementation gap. Thus, it is important for future researches to be aimed at the optimization of materials and/or resources that allow the microgrid market to be accessible for all users in the energetic value chain. This way, the formulation of its performance criteria such as the optimization of issues and the use of modern optimization algorithms are recommendable when it comes to integrating small, medium or high scale projects. 


\section{ACKNOWLEDGEMENTS}

The authors of this article wish to thank Colciencias and the Universidad Distrital Francisco José de Caldas for funding resources to develop this research project.

\section{REFERENCES}

[1] J. P. Dorian, H. T. Franssen, and D. R. Simbeck, "Global challenges in energy," Energy Policy, vol. 34, no. 15, pp. 1984-1991, 2006.

[2] D. L. Goodstein, Out of gas: the end of the age of oil. WW Norton \& Company, 2005.

[3] A. K. Basu, S. P. Chowdhury, S. Chowdhury, and S. Paul, "Microgrids: Energy management by strategic deployment of DERs-A comprehensive survey," Renew. Sustain. Energy Rev., vol. 15, no. 9, pp. 4348-4356, 2011.

[4] I. E. T. R. E. Series, "Microgrids and active distribution networks," Inst. Eng. Technol., 2009

[5] B. K. Bala and S. A. Siddique, "Optimal design of a PV-diesel hybrid system for electrification of an isolated island-Sandwip in Bangladesh using genetic algorithm," Energy Sustain. Dev., vol. 13, no. 3, pp. 137-142, 2009.

[6] H. A. Rahman, M. S. Majid, A. R. Jordehi, G. C. Kim, M. Y. Hassan, and S. O. Fadhl, "Operation and control strategies of integrated distributed energy resources: A review,” Renew. Sustain. Energy Rev., vol. 51, pp. 1412-1420, 2015.

[7] L. Ye, H. B. Sun, X. R. Song, and L. C. Li, "Dynamic modeling of a hybrid wind/solar/hydro microgrid in EMTP/ATP," Renew. Energy, vol. 39, no. 1, pp. 96-106, 2012.

[8] P. Basak, S. Chowdhury, S. H. nee Dey, and S. P. Chowdhury, "A literature review on integration of distributed energy resources in the perspective of control, protection and stability of microgrid," Renew. Sustain. Energy Rev., vol. 16, no. 8, pp. 5545-5556, 2012.

[9] F. Z. Peng, Y. W. Li, and L. M. Tolbert, "Control and protection of power electronics interfaced distributed generation systems in a customer-driven microgrid," in Power \& Energy Society General Meeting, 2009. PES'09. IEEE, 2009, pp. 1-8.

[10] M. Jabeen, M. Umar, M. Zahid, M. U. Rehaman, R. Batool, and K. Zaman, "Socio-economic prospects of solar technology utilization in Abbottabad, Pakistan,” Renew. Sustain. Energy Rev., vol. 39, pp. 1164-1172, 2014.

[11] D. Seifried and W. Witzel, Renewable energy: the facts. Routledge, 2010.

[12] J. Padulles, G. W. Ault, and J. R. McDonald, "An approach to the dynamic modelling of fuel cell characteristics for distributed generation operation," in Power Engineering Society Winter Meeting, 2000. IEEE, 2000, vol. 1, pp. 134-138.

[13] S. Mohammadi, S. Soleymani, and B. Mozafari, "Scenario-based stochastic operation management of microgrid including wind, photovoltaic, micro-turbine, fuel cell and energy storage devices," Int. J. Electr. Power Energy Syst., vol. 54, pp. 525-535, 2014.

[14] C.-S. Moo, K. S. Ng, and Y.-C. Hsieh, "Parallel operation of battery power modules," IEEE Trans. Energy Convers., vol. 23, no. 2, pp. 701-707, 2008

[15] C. Marnay, F. J. Rubio, and A. S. Siddiqui, "Shape of the microgrid," Lawrence Berkeley Natl. Lab., 2000.

[16] P. Piagi and R. H. Lasseter, "Autonomous control of microgrids," in 2006 IEEE Power Engineering Society General Meeting, 2006, p. 8-pp.

[17] A. P. S. Meliopoulos, "Challenges in simulation and design of $\mu$ Grids," in Power Engineering Society Winter Meeting, 2002. IEEE, 2002, vol. 1, pp. 309-314.

[18] M. W. Davis, "Mini gas turbines and high speed generators a preferred choice for serving large commercial customers and microgrids. I. Generating system," in Power Engineering Society Summer Meeting, 2002 IEEE, 2002, vol. 2, pp. 669-676.

[19] O. Palizban, K. Kauhaniemi, and J. M. Guerrero, "Microgrids in active network management-Part I: Hierarchical control, energy storage, virtual power plants, and market participation,” Renew. Sustain. Energy Rev., vol. 36, pp. 428-439, 2014.

[20] O. Bailey, C. Creighton, R. Firestone, C. Marnay, and M. Stadler, "Distributed Energy Resources in Practice: A Case Study Analysis and Validation of LBNL's Customer Adoption Model," Lawrence Berkeley Natl. Lab., 2003.

[21] A. S. Siddiqui, R. M. Firestone, S. Ghosh, M. Stadler, J. L. Edwards, and C. Marnay, "Distributed energy resources customer adoption modeling with combined heat and power applications," Lawrence Berkeley Natl. Lab., 2003.

[22] R. H. Lasseter and P. Paigi, "Microgrid: a conceptual solution," in Power Electronics Specialists Conference, 2004. PESC 04.2004 IEEE 35th Annual, 2004, vol. 6, pp. 4285-4290.

[23] R. Firestone and C. Marnay, "Energy manager design for microgrids," Lawrence Berkeley Natl. Lab., 2005.

[24] Z. Jiang, "Agent-based control framework for distributed energy resources microgrids," in 2006 IEEE/WIC/ACM International Conference on Intelligent Agent Technology, 2006, pp. 646-652.

[25] Z. Jiang and X. Yu, "Hybrid DC-and AC-linked microgrids: towards integration of distributed energy resources," in Energy 2030 Conference, 2008. ENERGY 2008. IEEE, 2008, pp. 1-8.

[26] M. R. Vallem, J. Mitra, and S. B. Patra, "Distributed generation placement for optimal microgrid architecture," in 2005/2006 IEEE/PES Transmission and Distribution Conference and Exhibition, 2006, pp. 1191-1195.

[27] B. Meyer, Y. Bamberger, and I. Bel, "Electricite de France and integration of distributed energy resources," in 2006 IEEE Power Engineering Society General Meeting, 2006.

[28] M. S. Jimenez and N. Hatziargyriou, "Research activities in Europe on integration of distributed energy resources in the electricity networks of the future," in 2006 IEEE Power Engineering Society General Meeting, 2006, p. 4-pp.

[29] K. Strunz, "Developing benchmark models for studying the integration of distributed energy resources," in 2006 IEEE Power Engineering Society General Meeting, 2006, p. 2-pp.

[30] Z. Jiang and R. A. Dougal, "Hierarchical microgrid paradigm for integration of distributed energy resources," in Power and Energy Society General Meeting-Conversion and Delivery of Electrical Energy in the 21st Century, 2008 IEEE, 2008, pp. 1-8.

[31] H. Jiayi, J. Chuanwen, and X. Rong, "A review on distributed energy resources and MicroGrid," Renew. Sustain. Energy Rev., vol. 12, no. 9 , pp. $2472-2483,2008$

[32] A. A. Zaidi and F. Kupzog, "Microgrid automation-a self-configuring approach," in Multitopic Conference, 2008. INMIC 2008. IEEE International, 2008 , pp. 565-570.

[33] A. Vaccaro, M. Popov, D. Villacci, and V. Terzija, "An integrated framework for smart microgrids modeling, monitoring, control, communication, and verification," Proc. IEEE, vol. 99, no. 1, pp. 119-132, 2011.

[34] D. Quiggin, S. Cornell, M. Tierney, and R. Buswell, "A simulation and optimisation study: Towards a decentralised microgrid, using real world fluctuation data," Energy, vol. 41, no. 1, pp. 549-559, 2012.

[35] H. Lund, A. N. Andersen, P. A. Østergaard, B. V. Mathiesen, and D. Connolly, "From electricity smart grids to smart energy systemsa market operation based approach and understanding," Energy, vol. 42, no. 1, pp. 96-102, 2012.

[36] P. Siano, "Demand response and smart grids-A survey," Renew. Sustain. Energy Rev., vol. 30, pp. 461-478, 2014.

[37] A. R. Di Fazio, T. Erseghe, E. Ghiani, M. Murroni, P. Siano, and F. Silvestro, "Integration of renewable energy sources, energy storage systems, and electrical vehicles with smart power distribution networks," J. Ambient Intell. Humaniz. Comput., vol. 4, no. 6, pp. 663-671, 2013. 
[38] J. J. Justo, F. Mwasilu, J. Lee, and J.-W. Jung, "AC-microgrids versus DC-microgrids with distributed energy resources: A review," Renew. Sustain. Energy Rev., vol. 24, pp. 387-405, 2013.

[39] A. Saif, V. R. Pandi, H. H. Zeineldin, and S. Kennedy, "Optimal allocation of distributed energy resources through simulation-based optimization," Electr. Power Syst. Res., vol. 104, pp. 1-8, 2013.

[40] A. Rezaee Jordehi and J. Jasni, "Parameter selection in particle swarm optimisation: a survey," J. Exp. Theor. Artif. Intell., vol. 25, no. 4, pp. 527-542, 2013.

[41] A. R. Jordehi, J. Jasni, N. I. A. Wahab, and M. Z. A. A. Kadir, "Particle swarm optimisation applications in FACTS optimisation problem," in Power Engineering and Optimization Conference (PEOCO), 2013 IEEE 7th International, 2013, pp. 193-198.

[42] A. Omu, R. Choudhary, and A. Boies, "Distributed energy resource system optimisation using mixed integer linear programming," Energy Policy, vol. 61, pp. 249-266, 2013.

[43] M. R. Aghamohammadi and H. Abdolahinia, "A new approach for optimal sizing of battery energy storage system for primary frequency control of islanded microgrid," Int. J. Electr. Power Energy Syst., vol. 54, pp. 325-333, 2014.

[44] W. Gu, Z. Wu, R. Bo, W. Liu, G. Zhou, W. Chen, and Z. Wu, "Modeling, planning and optimal energy management of combined cooling, heating and power microgrid: A review," Int. J. Electr. Power Energy Syst., vol. 54, pp. 26-37, 2014.

[45] W. Su and J. Wang, "Energy management systems in microgrid operations," Electr. J., vol. 25, no. 8, pp. 45-60, 2012.

[46] N. Pogaku, M. Prodanovic, and T. C. Green, "Modeling, analysis and testing of autonomous operation of an inverter-based microgrid," IEEE Trans. power Electron., vol. 22, no. 2, pp. 613-625, 2007.

[47] S. Chowdhury and P. Crossley, Microgrids and active distribution networks. The Institution of Engineering and Technology, 2009.

[48] J. Jasni and A. R. Jordehi, "A comprehensive review on methods for solving FACTS optimization problem in power systems.," Int. Rev. Electr. Eng., vol. 6, no. 4, pp. 1916-1926, 2011.

[49] A. R. Jordehi and J. Jasni, "Approaches for FACTS optimization problem in power systems," in Power Engineering and Optimization Conference (PEDCO) Melaka, Malaysia, 2012 Ieee International, 2012, pp. 355-360.

[50] F. D. Kanellos, A. I. Tsouchnikas, and N. D. Hatziargyriou, "Micro-grid simulation during grid-connected and islanded modes of operation," in International Conference on Power Systems Transients, 2005, vol. 6.

[51] Y. W. Li, D. M. Vilathgamuwa, and P. C. Loh, "A grid-interfacing power quality compensator for three-phase three-wire microgrid applications," IEEE Trans. Power Electron., vol. 21, no. 4, pp. 1021-1031, 2006.

[52] R. M. Krishna and S. A. Daniel, "Design methodology for autonomous operation of a Micro-grid," in Electrical and Electronics Engineering, 2009. ELECO 2009. International Conference on, 2009, pp. I-40.

[53] M. Shahabi, M. R. Haghifam, M. Mohamadian, and S. A. Nabavi-Niaki, "Microgrid dynamic performance improvement using a doubly fed induction wind generator," IEEE Trans. Energy Convers., vol. 24, no. 1, pp. 137-145, 2009.

[54] R. Majumder, A. Ghosh, G. Ledwich, and F. Zare, "Power management and power flow control with back-to-back converters in a utility connected microgrid," IEEE Trans. Power Syst., vol. 25, no. 2, pp. 821-834, 2010.

[55] Q.-C. Zhong and G. Weiss, "Synchronverters: Inverters that mimic synchronous generators," IEEE Trans. Ind. Electron., vol. 58, no. 4, pp. 1259-1267, 2011.

[56] T. Logenthiran, D. Srinivasan, and A. M. Khambadkone, "Multi-agent system for energy resource scheduling of integrated microgrids in a distributed system," Electr. Power Syst. Res., vol. 81, no. 1, pp. 138-148, 2011.

[57] R. Zamora and A. K. Srivastava, "Controls for microgrids with storage: Review, challenges, and research needs," Renew. Sustain. Energy Rev., vol. 14, no. 7, pp. 2009-2018, 2010.

[58] M. Ross, R. Hidalgo, C. Abbey, and G. Joós, "Energy storage system scheduling for an isolated microgrid," IET Renew. power Gener., vol. 5, no. 2, pp. 117-123, 2011.

[59] J. M. Guerrero, J. C. Vasquez, J. Matas, L. G. De Vicuña, and M. Castilla, "Hierarchical control of droop-controlled AC and DC microgrids - A general approach toward standardization,” IEEE Trans. Ind. Electron., vol. 58, no. 1, pp. 158-172, 2011.

[60] E. Alvarez, A. M. Campos, P. Arboleya, and A. J. Gutiérrez, "Microgrid management with a quick response optimization algorithm for active power dispatch,” Int. J. Electr. Power Energy Syst., vol. 43, no. 1, pp. 465-473, 2012.

[61] M. Xia, X. He, and X. Zhang, "Design and implementation of a control strategy for microgrid containing renewable energy generations and electric vehicles," Math. Probl. Eng., vol. 2013, 2013.

[62] W. Gu, W. Liu, Z. Wu, B. Zhao, and W. Chen, "Cooperative control to enhance the frequency stability of islanded microgrids with DFIG-SMES,” Energies, vol. 6, no. 8, pp. 3951-3971, 2013

[63] J. M. Guerrero, P. C. Loh, T.-L. Lee, and M. Chandorkar, "Advanced Control Architectures for Intelligent Microgrids \#x2014;Part II: Power Quality, Energy Storage, and AC/DC Microgrids," IEEE Trans. Ind. Electron., vol. 60, no. 4, pp. 1263-1270, 2013.

[64] A. Choudar, D. Boukhetala, S. Barkat, and J.-M. Brucker, "A local energy management of a hybrid PV-storage based distributed generation for microgrids," Energy Convers. Manag., vol. 90, pp. 21-33, 2015.

[65] M. A. Abdullah, K. M. Muttaqi, and A. P. Agalgaonkar, "Sustainable energy system design with distributed renewable resources considering economic, environmental and uncertainty aspects," Renew. Energy, vol. 78, pp. 165-172, 2015.

[66] M. Mehrasa, E. Pouresmaeil, H. Mehrjerdi, B. N. Jørgensen, and J. P. S. Catalão, "Control technique for enhancing the stable operation of distributed generation units within a microgrid," Energy Convers. Manag., vol. 97, pp. 362-373, 2015.

[67] G. Bayrak, "A remote islanding detection and control strategy for photovoltaic-based distributed generation systems," Energy Convers. Manag., vol. 96, pp. 228-241, 2015.

[68] H. Morais, T. Sousa, J. Soares, P. Faria, and Z. Vale, "Distributed energy resources management using plug-in hybrid electric vehicles as a fuel-shifting demand response resource," Energy Convers. Manag., vol. 97, pp. 78-93, 2015.

[69] C. F. Calvillo, A. Sánchez-Miralles, and J. Villar, "Assessing low voltage network constraints in distributed energy resources planning," Energy, vol. 84, pp. 783-793, 2015.

[70] S. A. Chowdhury, S. Aziz, S. Groh, H. Kirchhoff, and W. Leal Filho, "Off-grid rural area electrification through solar-diesel hybrid minigrids in Bangladesh: resource-efficient design principles in practice," J. Clean. Prod., vol. 95, pp. 194-202, 2015. 


\section{Author Profile}

Cesar Augusto Hernandez Suarez Electronic Engineer, Master in Information Science and Communications of the Universidad Distrital Francisco Jose de Caldas, Doctor of Philosophy in Systems and Computer Engineering of the Universidad Nacional de Colombia. Titular Professor and researcher at Universidad Distrital Francisco José de Caldas, Bogotá, Colombia.

Victor Alfonso Gomez Saavedra Electrical Engineer, Specialist in project management of the Universidad Distrital Francisco Jose de Caldas. Engineer of the Schneider Electric andProfessor at Universidad Distrital Francisco José de Caldas, Bogotá, Colombia.

Edwin Rivas Trujillo Electrical Engineer andMaster in Power Generation Systems at Universidad del Valle and Doctor of Philosophy in Electrical, Electronic and Automatic Engineering at Universidad Carlos III de Madrid.Titular Professor at Universidad Distrital Francisco José de Caldas, Bogotá, Colombia. 